\title{
Effects of Regular Coke and Coke Zero on Blood Glucose, Serum Lipid Profile and Activities of Serum Aminotransferases in Healthy Human Subjects
}

\author{
A. E. Ben-Chioma ${ }^{1}$, D. G. Tamuno-Emine ${ }^{2}$, A. S. Jack ${ }^{3}$ \\ Department of Medical Laboratory Science, Rivers State University of Science and Technology, Port Harcourt
}

\begin{abstract}
Regular coke and Coke zero were investigated for possible effects on blood glucose concentration, serum lipid profile and activities of serum aminotransferases (AST and ALT) of healthy human subjects. Different groups of the human subjects were fed Eva premium table water $(330 \mathrm{ml})$, regular coke $(330 \mathrm{ml})$ or coke zero $(330 \mathrm{ml})$ each day for 4 days. Results obtained showed that regular coke fed group exhibited significantly high blood glucose concentration $(p<0.05)$ while coke zero and water fed groups showed no significant difference ( $p>0.05$ ). Also both regular coke and coke zero showed a decrease in serum high density lipoprotein cholesterol concentration ( $p<0.05)$, an increase in serum total cholesterol concentration, low density lipoprotein cholesterol concentration and AST activity ( $p<0.05)$, and a statistically non-significant effect $(p>0.05)$ on serum ALT activity and triglycerides. Blood glucose concentration is a marker of diabetes mellitus while a rise in the activities of AST and ALT in the bloodstream gives an indication of failure of vital organs such as the heart and liver. Abnormal lipid profile parameters gives an indication of predisposure to cardiovascular diseases such as atherosclerosis. From the findings of this study, it can be concluded that high intake of regular coke and coke zero can predispose one to some diseases, notably organ failure, diabetes mellitus and atherosclerosis.
\end{abstract}

Keywords: Regular coke, Coke zero, Blood glucose, Serum aminotransferases, Predisposing factor, Human subjects.

\section{Introduction}

Coca-cola is a soft drink which is a sweetened water-based non-alcoholic beverage with balanced acidity (Vartanionet al., 2007). The coca-cola company manufactures several variations of coca-cola beverages usually shortened to "coke" by the general public. One of the most common version is the regular coke, but the company also makes flavoured variations and a non-calorie version coke zero (Richard, 2012).

The primary difference between Regular coke and Coke zero is the calorie and carbohydrate content. A 12-ounce serving of regular coke contain 140 calories and 39 grams of carbohydrate, while the same amount of coke zero contains no calories and no carbohydrate. This observation can be explained by the fact that coke zero is not made with sugar, which is what adds the calories and carbohydrate to regular coke.

Researchers have shown that high intake of sugar-sweetened soft drinks like coca cola can lead to increased risk of several disease states, including cardiovascular disease, obesity and type-2 diabetes (Gibson, 2008).

Diabetes mellitus is a chronic disease characterized by persistent hyperglycaemia and glycosuria and is the most prominent disease related to failure of blood sugar regulation. The disease was found to be uncommon in the African continent in the 1960, but in 1992 the Nigerian National Expert Committee on non-communicable diseases discovered a high prevalence of the disease in urban of areas of Nigeria (Santaguidaet al., 2008). This was ascribed to gradual westernization, with an increase in the number of soft drinks manufacturing companies. The traditional habit of giving water to a visitor is now being replaced with sweetened soft drinks like regular coke and coke zero, hence the need to assess the effects of these two coca cola brands on blood glucose concentration, serum lipid profile and the activities of serum aminotransferases, which are some of the several biochemical markers that can give valuable information about predisposure to diabetes mellitus, cardiovascular disease and hepatic dysfunction.

\section{Materials and Methods}

Coca cola Soft Drinks: The coca cola soft drinks (regular coke and coke zero) used in this study were obtained from a soft drink vendor in Port Harcourt, Nigeria during February, 2014. Each can of soft drink was chilled at a temperature of 2 to $4^{0} \mathrm{C}$ in a refrigerator before administration.

Study Participants: Thirty (30) healthy human subjects were recruited for this study. The study protocol was carefully explained to each subject and consent was given to participant in the study. The subjects consisted of 20 males and 10 females aged 20 to 45 years, with body mass index (BMI) ranging from 19.5 to $24.8 \mathrm{kgm}^{-2}$. All the study participants had fasting blood glucose concentration less than $5.5 \mathrm{mmol} / \mathrm{L}$ and none was currently using glucoselowering medications.

Study Design: The study participants fasted overnight and were divided into 3 groups, each group consisting of 10 persons.

Group 1 participants were given to drink on an empty stomach $330 \mathrm{ml}$ Eva premium table water (produced by Nigerian Bottling Company) each day for 5 days. 


\section{International Journal of Science and Research (IJSR) \\ ISSN (Online): 2319-7064 \\ Index Copernicus Value (2013): 6.14 | Impact Factor (2014): 5.611}

Group II participants were given to drink $330 \mathrm{ml}$ regular coke first thing in the morning for 5 days.

Group III participants were treated similarly to Group II, except that coke zero was given. Each participant in all the groups was asked to eat 2 hours after taking the test material.

Blood Test: Blood was collected from each participant before feeding with test material on the 1 st day and 2 hours after feeding on the $5^{\text {th }}$ day. The blood samples thus collected were transferred into:

i) Labelled tubes containing sodium fluoride anticoagulant for determination of plasma glucose concentrations using an assay kit supplied by Randox Laboratories, UK.

ii)Plain tubes and allowed to stand for about 15 minutes to clot before centrifuging at 3000rpm for 15 minutes at room temperature. Serum was separated using Pasteur pipette for the determination of serum aspartate aminotransferase (AST) and alanine aminotransferase (ALT) activities using kits of Randox Laboratories, UK, and for the determination of triglycerides, total cholesterol and high density lipoprotein (HDL) cholesterol concentrations using kits of Randox Laboratories, UK. Low density lipoprotein cholesterol (LDL -Cholesterol) concentration was calculated using the formula:

LDL-cholesterol $=$ Total cholesterol $-($ HDL Cholesterol + $0.46 \mathrm{x}$ triglycerides) (All in $\mathrm{mmol} / \mathrm{L})$.

Statistical Analysis: All values were expressed as mean \pm standard error of mean (SEM) and statistically analyzed using student t-distribution test. Differences were considered significant at $\mathrm{p}<0.005$.

\section{Results}

The effects of regular coke and coke zero on blood glucose concentrations of human subjects are shown in Table 1. In subjects fed regular coke, the blood glucose concentration increased significantly $(\mathrm{p}<0.05)$ from $3.94 \pm 0.52 \mathrm{mmol} / \mathrm{L}$ to $5.2 \pm 0.73 \mathrm{mmol} / \mathrm{L}$. However, in subjects fed coke zero, the blood glucose concentration was found to show no significant difference $(\mathrm{p}>0.05)$ when the pre-treatment value of $3.94 \pm 0.52 \mathrm{mmol} / \mathrm{L}$ was compared with the posttreatment value of $3.99 \pm 0.54 \mathrm{mmol} / \mathrm{L}$. Similarly, in subjects fed water, no significant difference $(p>0.05)$ was observed between the pre-treatment value of $4.10 \pm 0.27$ $\mathrm{mmol} / \mathrm{L}$ and the post-treatment value of $4.18 \pm 0.28 \mathrm{mmol} / \mathrm{L}$.

Table 2 showed the result for serum aminotransferase activities, in which both regular coke and coke zero fed groups exhibited statistically significant increase $(p<0.05)$ in serum aspartate aminotransferase (AST) activity.

For regular coke fed group, the AST activity changed from $5.30 \pm 0.41 \mathrm{IU} / \mathrm{L}$ to $9.00 \pm 0.72 \mathrm{IU} / \mathrm{L}$ while the activity for coke zero fed group changed from $5.33 \pm 0.41 \mathrm{IU} / \mathrm{L}$ to 7.33 $\pm 0.43 \mathrm{IU} / \mathrm{L}$. For the group fed water, the AST activity changed non-significantly from $7.90 \pm 0.63 \mathrm{IU} / \mathrm{L}$ to $8.30 \pm$ $1.30 \mathrm{IU} / \mathrm{L}$.
Water, regular coke and coke zero respectively were not found to show any statistically significant difference ( $p>$ 0.05 ) in the activity of serum ALT when the treatment value of each group was compared with the post-treatment value.

In table 3 , it was observed that both regular coke and coke zero fed groups exhibited a significant increase $(\mathrm{p}<0.05)$ in serum total cholesterol and LDL-cholesterol concentrations, and a significant decrease $(\mathrm{p}<0.05)$ in serum HLDcholesterol concentration. For regular coke fed group, the serum total cholesterol concentration changed from $4.67 \pm$ 0.62 to $5.19 \pm 0.50 \mathrm{mmol} / \mathrm{L}$ while $\mathrm{LDL}$-cholesterol changed from $1.85 \pm 0.54$ to $2.71 \pm 0.16 \mathrm{mmol} / \mathrm{L}$. The HDLcholesterol concentration changed from $2.37 \pm 0.34$ to 1.81 $\pm 0.12 \mathrm{mmol} / \mathrm{L}$.

For coke zero fed group, the serum total cholesterol concentration changed from $3.92 \pm 1.48$ to $4.51 \pm 0.26$ $\mathrm{mmol} / \mathrm{L}$ while the LDL-cholesterol concentration changed from $1.73 \pm 0.56$ to $3.05 \pm 0.29 \mathrm{mmol} / \mathrm{L}$. The HDLcholesterol concentration changed from $2.12 \pm 0.27$ to 1.01 $\pm 0.13 \mathrm{mmol} / \mathrm{L}$.

Comparison between the pre-treatment and post-treatment values of serum triglycerides concentrations showed that neither regular coke nor coke zero induced a statistically significant difference $(\mathrm{p}>0.05)$.

Table 1: Effect of regular coke and coke zero on blood glucose concentration of healthy human subjects

\begin{tabular}{|c|c|c|}
\hline Group fed & \multicolumn{2}{|c|}{ Blood glucose concentration mmol/L } \\
\hline & Before $($ Day 1$)$ & After $($ Day 5) \\
\hline Water & $4.10 \pm 0.27$ & $4.18 \pm 0.28$ \\
\hline Regular coke & $3.94 \pm 0.52^{\mathrm{a}}$ & $5.2 \pm 0.73^{\mathrm{b}}$ \\
\hline Coke zero & $3.94 \pm 0.52$ & $3.99 \pm 0.54$ \\
\hline
\end{tabular}

All values are expressed as mean \pm SEM for 10 human subjects. Means within each row were compared for significant differences using subject $\mathrm{T}$-distribution test. $\mathrm{a}, \mathrm{b}$ $=$ statistically significant difference $(\mathrm{p}<0.05)$.

Table 2: Activities of serum aspartate aminotransferase (AST) and alanine aminotransferase (ALT) of human subjects fed two brands of coke.

\begin{tabular}{|c|c|c|c|}
\hline Group fed & Day & \multicolumn{2}{|c|}{ Serum activity (IU/L) } \\
\hline & & AST & ALT \\
\hline Water & 0 & $7.90 \pm 0.63$ & $4.80 \pm 0.61$ \\
& 5 & $8.30 \pm 1.30$ & $4.30 \pm 0.43$ \\
\hline Regular coke & 0 & $5.30 \pm 0.41^{\mathrm{a}}$ & $3.33 \pm 0.47$ \\
& 5 & $9.00 \pm 0.72^{\mathrm{b}}$ & $4.03 \pm 0.56$ \\
\hline Coke zero & 0 & $5.33 \pm 0.41^{\mathrm{c}}$ & $3.33 \pm 0.47$ \\
& 5 & $7.33 \pm 0.43^{\mathrm{d}}$ & $3.90 \pm 0.53$ \\
\hline
\end{tabular}

All values are expressed as mean \pm SEM for 10 human subjects. Means within each group were compared for significant differences using student $\mathrm{T}$-distribution test. Means in each group with different superscripts are significantly different $(\mathrm{p}<0.05)$. 


\section{International Journal of Science and Research (IJSR) \\ ISSN (Online): 2319-7064}

Index Copernicus Value (2013): 6.14 | Impact Factor (2014): 5.611

Table 3: Serum lipid profile of human subjects fed regular coke and coke zero respectively

\begin{tabular}{|c|c|c|c|c|c|}
\hline Group fed & Day & \multicolumn{4}{|c|}{ Serum lipid concentrations (mmol/L) } \\
\hline & & Total chol. & TG & HDL-Chol & LDL-chol \\
\hline Water & 0 & $3.40 \pm 0.25$ & $0.98 \pm 0.12$ & $1.27 \pm 0.15$ & $1.0 \pm 0.11$ \\
& 5 & $3.42 \pm 0.44$ & $1.02 \pm 0.28$ & $0.96 \pm 0.09$ & $2.10 \pm 0.39$ \\
\hline Regular coke & 0 & $4.67 \pm 0.62^{\mathrm{a}}$ & $0.97 \pm 0.06$ & $2.37 \pm 0.34^{\mathrm{e}}$ & $1.85 \pm 0.54^{\mathrm{k}}$ \\
& 5 & $5.19 \pm 0.15^{\mathrm{b}}$ & $1.20 \pm 0.27$ & $1.81 \pm 0.12^{\mathrm{f}}$ & $2.71 \pm 0.16^{1}$ \\
\hline Coke zero & 0 & $3.92 \pm 1.48^{\mathrm{c}}$ & $1.09 \pm 0.28$ & $2.12 \pm 0.27^{\mathrm{g}}$ & $1.73 \pm 0.56^{\mathrm{m}}$ \\
& 5 & $4.51 \pm 0.15^{\mathrm{d}}$ & $0.98 \pm 0.19$ & $1.01 \pm 0.13^{\mathrm{h}}$ & $3.05 \pm 0.29^{\mathrm{n}}$ \\
\hline
\end{tabular}

All values are expressed as mean \pm SEM for 10 human subjects. Means within each group were compared for significant differences using student T-distribution test. Means with different superscripts within each group differed significantly $(\mathrm{p}<0.05)$.

Total chol $=$ serum total cholesterol

$\mathrm{TG}=$ serum triglycerides

$\mathrm{HDL}=$ High density lipoprotein cholesterol

$\mathrm{LDL}=$ Low density lipoprotein cholesterol

\section{Discussion}

Studies have shown that high intake of sugar-sweetened soft drinks has the potential of increasing fasting blood glucose concentration and can predispose one to several disease states, including obesity, type-2 diabetes and cardiovascular disease (Gibson, 2008; Laughlin et al., 2014). Evidence from this study showed that human subjects fed regular coke had a significant increase $(p<0.05)$ in blood glucose concentration. Regular coke is a soft drink with added sugars either in the form of sucrose or high fructose corn syrup. Epidemiological studies have shown that consumption of sugar or sugar-sweetened beverages is associated with unfavourable lipid concentrations, insulin resistance, fatty liver disease, type-2 diabetes, cardiovascular disease and metabolic syndrome (Yoshida et al., 2007). These findings clearly showed that the intake of regular coke cannot be safe for diabetes or people with diabetic history (Jaiprakashet al., 1993).

Coke zero, on the other hand, exerted no influence on blood glucose concentration of healthy human subjects (Table 1). This can be attributed to the fact that coke zero has a low calorie content and no added sugars. However, evidence from some studies suggest that the aspartame content of coke zero can increase food intakes by both humans and animals, and when taken indiscriminately could lead to an abnormally raised blood glucose concentration and an abnormal lipid profile parameters.

Ordinarily, hepatotoxic agents cause the release of certain enzymes (e.g. aspartate aminotransferase, AST, alanine aminotransferase ALT, etc) into the bloodstream as a result of damage to liver cells (Moore et al., 1985).From the findings of this study, both coke zero and regular coke induced a significant increase in serum AST activity and a non-significant effect on serum ALT activity. AST appears in high concentrations in a number of tissues (liver, kidneys, heart and pancreas) and is released slowly in comparison to ALT. But since ALT is localized primarily in the cytosol of hepatocytes (liver cells), this enzyme is considered a more sensitive marker of hepatocellular damage than AST (AlMamaryet al., 2002). Now, as both regular coke and coke zero exhibited a high serum AST activity only, it can be said that this action may reflect a mild toxicity which permitted leakage of the enzyme from tissues other than the liver into the bloodstream.

In the analysis of lipid profile, both regular coke and coke zero were found to exhibit an increase in serum total cholesterol and LDL-cholesterol concentrations, a decrease in HDL-cholesterol concentration and a normal level of serum triglycerides. The increased total cholesterol and LDL-cholesterol concentrations and reduced HDLcholesterol concentration observed could be suggestive of the fact that the two coke products have the potential tendencies of predisposing people to type-2 diabetes, atherosclerosis and other cardiovascular diseases, since lipid abnormalities are common in such conditions (Konstantinos, 2012).

\section{Conclusion}

The findings of this study have shown that regular coke and coke zero are likely to predispose one to some diseases. Regular coke, in particular, was observed to increase the concentration of blood glucose, which is a marker of diabetes mellitus. Also, the decreased serum HDLcholesterol and increased serum total cholesterol, LDLcholesterol and AST activity showed by both coke products may reflect lipid profile abnormality and a mild toxic effect on organs other than the liver that elaborate AST.

\section{Acknowledgement}

The authors gratefully acknowledge the good secretarial work of Happiness Michael.

\section{References}

[1] Al-Mamary, M., Al-Habori, M., Al-Aghabari, A. M. and Baker, M. M. (2002). Investigation into the toxicological effects of cataedulis leaves: A short-term study in animals.Phytother Res. 16, 127 - 132.

[2] Gibson, S. (2008). Sugar-sweetened soft drinks and obesity: A systematic review of the evidence from observational studies and interventions. Nutrition Research Reviews, 21(2), 134 - 147.

[3] Jaiprakash, J., Thomas, P., Cavan, D. and Keer, D. (1993). Preventing childhood obesity by reducing consumption of carbonated drinks: Cluster randomized controlled trial. British Medical Journal, 328(7450), 1237.

[4] Konstantinos, L. (2012). Aretaeus of Cappadocia and the first description of diabetes.Hormones, 11(1), $109-$ 113. 


\section{International Journal of Science and Research (IJSR) \\ ISSN (Online): 2319-7064}

Index Copernicus Value (2013): 6.14 | Impact Factor (2014): 5.611

[5] Laughlin, M. R. (2014). Normal roles for dietary fructose in carbohydrate metabolism.Nutrients, 6(8), $3117-3129$.

[6] Moore, M., Thor, H., Moore, G., Nelson, S., Moldeus, P. and Orrhenius, S. (1985). The toxicity of acetaminophen and $\mathrm{N}$-acetyl p-benzoquinoneimine in isolated hepatocytes is associated with the depletion and increased cytosolic $\mathrm{Ca}^{2+}$. Journal of Biological Chemistry, 260, 13035 - 13040.

[7] Richard, G. (2012). Origin of coca-cola Columbus Georigia.Journal of Christmas Ideology and Popular Culture, 4, $50-70$

[8] Santaguida, P. L., Balion, C., Hunt, D., Morrison, K., Gerstein, H., Raina, P., Booker, L. and Yazdi, H. (2008). Diagnosis, prognosis and treatment of impaired glucose tolerance fasting glucose.Summary of Evidence Report/Technology Assessment, No. 128 agency for healthcare Research and Quality.

[9] Vartanion, L. R., Schwartz, M. B. and Brownell, K. D. (2007). Effects of soft drink consumption on nutrition and health: A systematic review and meta-analysis. American Journal of Public Health, 97(4), 667 - 675.

[10] Yoshida, M., Mckeown, N. M., Rogers, G., Meigs, J. B., Saltzman, E., D’Agostino, R. and Jacques, P. F. (2007). Surrogate markers of insulin resistance are associated with consumption of sugar sweetened drinks and juices in middle and older aged adults. Journal of Clinical Nutrition, 137, 2121 - 2127. 